\title{
Description of Ruminococcus catenae SW178 sp. nov., a new anaerobic species isolated from
}

\section{feral chicken}

Supapit Wongkuna ${ }^{1,2,3}$, Sudeep Ghimire ${ }^{1,2}$, Surang Chankhamhaengdecha ${ }^{4}$, Tavan Janvilisri ${ }^{3}$, Joy Scaria $^{1,2 *}$

${ }^{1}$ Department of Veterinary and Biomedical Sciences, South Dakota State University, Brookings, SD, USA.

${ }^{2}$ South Dakota Center for Biologics Research and Commercialization, SD, USA.

${ }^{3}$ Department of Biochemistry, Faculty of Science, Mahidol University, Bangkok, Thailand

${ }^{4}$ Department of Biology, Faculty of Science, Mahidol University, Bangkok, Thailand

*Address correspondence to: Joy Scaria

Email: joyscaria@gmail.com

\begin{abstract}
A Gram-positive, obligately anaerobic coccobacillus, with the white raised circular colony was isolated from the cecum of feral chickens in Brookings, South Dakota, USA. The 16S rRNA gene sequence analysis suggested that the closest species to strain SW178 was Ruminococcus torques ATCC $27756^{\mathrm{T}}$ (96.94\% similarity) that belongs to the family Lachnospiraceae. The genome of strain SW178 is $3.18 \mathrm{Mbp}$ with $\mathrm{G}+\mathrm{C}$ content of $46.9 \mathrm{~mol} \%$. Based on the phylogenetic and phenotypic comparison, we propose that strain SW178 be assigned to the genus Ruminococcus as a novel species, for which the name Ruminococcus catenae is proposed. The type strain is $\operatorname{SW} 178$ (= CCOS $1886^{\mathrm{T}}$, $=$ DSM $109242^{\mathrm{T}}$ ).
\end{abstract}




\section{Introduction}

The bacterial community in the gastrointestinal tract of animals provide gut health benefits such as development of immune system, pathogen exclusion and digestion of polysaccharides $(1,2)$. Recent advancements in sequencing technology have helped to define overall gut microbiome composition of humans animals using metagenomics $(3,4)$. However, isolation and cultivation of gut microbiota composition are crucial to determine the phenotypic characteristics of individual species and to identify ecological interactions between microbes and the host $(5,6)$. Availability of cultured diversity also helpful for the development of probiotics. Herein, we report the isolation and taxonomic characterization of a new anaerobic bacterium from the cecum of feral chicken. We propose Ruminococcus catenae sp. nov. strain SW178 $\left(=\operatorname{CCOS} 1886^{\mathrm{T}},=\mathrm{DSM} 109242^{\mathrm{T}}\right)$ as a new member of genus Ruminococcus.

\section{Isolation and Ecology}

Strain SW178 was isolated from the cecum of feral chicken. For cultivation, fresh cecal content was transferred within 10 minutes of the collection into an anaerobic workstation (Coy Labs, USA) containing $85 \%$ nitrogen, $10 \%$ hydrogen and $5 \square \%$ carbon dioxide. Modified Brain Heart Infusion (BHI-M) medium containing $37 \mathrm{~g} / \mathrm{L}$ of BHI, $5 \mathrm{~g} / \mathrm{L}$ of yeast extract, $1 \mathrm{ml}$ of $1 \mathrm{mg} / \mathrm{ml}$ menadione, 0.3 $\mathrm{g}$ of L-cysteine, $1 \mathrm{ml}$ of $0.25 \mathrm{mg} / \mathrm{L}$ of resazurin, $1 \mathrm{ml} \mathrm{of} 0.5 \mathrm{mg} / \mathrm{ml} \mathrm{hemin,} 10 \mathrm{ml}$ of vitamin and mineral mixture, $1.7 \mathrm{ml}$ of $30 \mathrm{mM}$ acetic acid, $2 \mathrm{ml}$ of $8 \mathrm{mM}$ propionic acid, $2 \mathrm{ml}$ of $4 \mathrm{mM}$ butyric acid, $100 \mu 1$ of $1 \mathrm{mM}$ isovaleric acid, and $1 \%$ of pectin and inulin was used for isolation. The strain was maintained in BHI-M medium and stored with $10 \%(\mathrm{v} / \mathrm{v})$ Dimethyl Sulfoxide (DMSO) at $-80^{\circ} \mathrm{C}$. Reference strain $R$. torques ATTCC $27756^{\mathrm{T}}$, obtained from the American Type Culture Collection (ATCC), was maintained under the same conditions.

\section{S rRNA phylogeny}


Genomic DNA of strain SW178 was extracted using a DNeasy Blood \& Tissue kit (Qiagen), according to the manufacturer's instructions. The 16S rRNA gene sequence was amplified using universal primer set 27F (5'- AGAGTTTGATCMTGGCTCAG-3'; Lane et al., 1991) and 1492R (5'ACCTTGTTACGACTT- 3'; Stackebrandt et al., 1993) (7, 8), and sequenced using a Sanger sequencer (ABI 3730XL; Applied Biosystems). The 16S rRNA gene sequence of SW165 was then compared with closely related strains from the GenBank (www.ncbi.nlm.nih.gov/genbank/) and EZtaxon databases (www.ezbiocloud.net/eztaxon) (9). Alignment and phylogenetic analysis were conducted using MEGA7 software (10). Multiple sequence alignments were generated using the CLUSTAL-W (11). The phylogeny was constructed using the maximum-likelihood (ML) (12), maximum-parsimony (MP) (13), and neighbour-joining (NJ) (14) methods. The distance matrices were generated according to Kimura's two-parameter model. Bootstrap resampling analysis of 1000 replicates was performed to estimate the confidence of the tree topologies. Based on 16S rRNA gene sequencing, the closest taxon related to SW178 was Ruminococcus torques ATCC $27756^{\mathrm{T}}$ with 96.94\% similarity. The results of phylogenetic tree analysis showed that SW178 clustered within the Merditerraneibacter (Ruminococcus) indicating that SW178 represents a novel member of this genus (Fig. 1).

\section{Genome features}

The whole genome sequencing of strain SW178 was performed on Illumina MiSeq sequencer with MiSeq Reagent Kit V3 chemistry. The reads were assembled using Unicycler that builds an initial assembly graph from short reads using the de novo assembler SPAdes 3.11.1 (15). The quality assessment for the assemblies was performed using QUAST (16).The draft genome sequence of strain SW451 has a total length of $3.18 \mathrm{Mbp}$. The genomic G+C content of SW178 was $46.9 \square \mathrm{mol} \%$. In addition, the average nucleotide identity (ANI) was calculated between SW178 and the closely related taxa using OrthoANI software (17). The ANI values were significantly less than the proposed ANI cutoff of 95-96ロ\% (18) demonstrating strain SW178 as a novel species within the genus 


\section{Physiology and Chemotaxonomy}

Colony morphology was determined after 2-3 days of incubation on BHI-M agar plates. Gramstaining was performed using a Gram-Straining kit (Difco), according to the manufacturer's instructions. Cell morphologies of cultures during exponential growth were examined by scanning electron microscopy (SEM). Aerotolerance was examined by incubating cultures for 2 days under aerobic and anaerobic conditions. Growth of strain SW178 at 4, 20, 30, 37, 40 and $55^{\circ} \mathrm{C}$ was observed. To determine $\mathrm{pH}$ range, the $\mathrm{pH}$ of the medium was adjusted to $\mathrm{pH} \square 4-9$ with sterile anaerobic solutions of $0.1 \square \mathrm{M} \mathrm{HCl}$ and $0.1 \mathrm{M} \mathrm{NaOH}$. Motility of this microorganism was determined using motility medium with triphenyltetrazolium chloride (TTC) (19). The growth was indicated by the presence of red color, reduced form of TTC after it is absorbed into the bacterial cell wall. Other biochemical tests; utilization of various substrates and enzyme activities were determined using the AN MicroPlate (Biolog) and API ZYM (bioMérieux) according to the manufacturer's instructions. For cellular fatty acid analysis, strain SW451 was cultured in BHI-M medium at $37 \square{ }^{\circ} \mathrm{C}$ for $24 \square \mathrm{h}$ under anaerobic condition. Cellular fatty acids were obtained from cell biomass and analyzed by GC (Agilent 7890A) according to the manufacturer's instruction of Microbial Identification System (MIDI) (20).

Cells of the strain SW178 were Gram-positive coccobacilli with $0.5-1.0 \mu \mathrm{m}$ (Fig. 3). Colonies on BHI-M agar were white, raised and entire edge with $0.2-0.5 \mathrm{~cm}$ in diameter. Strain SW178 grew between $37^{\circ} \mathrm{C}$ and $45^{\circ} \mathrm{C}$ with optimum growth at $45^{\circ} \mathrm{C}$. The optimum $\mathrm{pH}$ for the growth was 7.5 , and growth was observed at $\mathrm{pH} \square 6.5-7.5$. The strain could grow only under anaerobic condition indicating an obligately anaerobic bacterium. Based on the results obtained in Biolog tests, strain SW178 utilized dextrin, L-fucose, D-galacturonic, $\alpha$-D-Glucose, L-rhamnose, and D-sorbitol. The strain SW178 exhibited positive reactions for esterase (C4), esterase lipase (C8), $\beta$-galactosidase, $\alpha$ glucosidase and $\beta$-glucosidase on API ZYM plate (Table 1). The predominant cellular fatty acids of the strain SW178 included $\mathrm{C}_{14 \square: \square 0}(28.71 \%), \mathrm{C}_{16 \square: \square 0}(19.55 \%)$ and $\mathrm{C}_{16 \square: \square 0}$ DMA (12.55\%), in which differs from the reference strain (Table 2). 
Based on the genotypic and phenotypic features of strains SW178 and Ruminococcus torques ATCC $27756^{\mathrm{T}}$, we propose that strain SW178 should be described as a new member of the genus Ruminococcus. We assign strain SW178 as the type strain of the new species, for which the name Ruminococcus catenae is proposed.

\section{Description of Ruminococcus catenae SW178 sp. nov.}

Ruminococcus catenae SW178 sp. nov. (L. Pl. n. catenae, referring to cells growing in chains). The strain is strictly anaerobic, Gram-strain-positive and non-motile. The average size of each cell is $0.5-$ $1.0 \mu \mathrm{m}$, oval-shaped, and growing in chains. Colonies are visible on BHI-M agar after 2 days and are approximately $0.1-0.3 \mathrm{~cm}$ in diameter, white, raised and circular with entire edge. The microorganism exhibits optimal growth in BHI-M medium at $45^{\circ} \mathrm{C}$ and $\mathrm{pH}$ 7.5. The strain utilizes dextrin, L-fucose, D-galacturonic, $\alpha$-D-Glucose, L-rhamnose and D-sorbitol. The primary cellular fatty acids are $\mathrm{C}_{14 \square: \square 0}$ , $\mathrm{C}_{16 \square: \square 0}$ and $\mathrm{C}_{16 \square: \square 0} \mathrm{DMA}$. The genome of this strain is $3.18 \mathrm{Mbp}$ with $46.9 \mathrm{~mol} \%$ of $\mathrm{G}+\mathrm{C}$ content. This strain was isolated from the cecum of feral chicken. The type strain is SW178 $\left(=\operatorname{CCOS} 1886^{\mathrm{T}}\right.$, $=\mathrm{DSM} 109242^{\mathrm{T}}$ )

\section{Protologue}

The 16S rRNA gene and genome sequence were deposited in GenBank under accession number MN133850 and PRJNA554364, respectively. The digitized protologue of the strain SW178 is TA01018.

\section{Acknowledgments}

This work was supported in part by the USDA National Institute of Food and Agriculture, Hatch projects SD00H532-14 and SD00R540-15, and a grant from the South Dakota Governor's Office of Economic Development awarded to JS. SW received support from the Science Achievement Scholarship of Thailand. 


\section{Conflicts of interest}

None to declare

\section{References}

1. Jandhyala SM, Talukdar R, Subramanyam C, Vuyyuru H, Sasikala M, Nageshwar Reddy D.

Role of the normal gut microbiota. World J Gastroenterol. 2015;21(29):8787-803.

2. Thursby E, Juge N. Introduction to the human gut microbiota. Biochem J.

2017;474(11):1823-36.

3. Qin J, Li R, Raes J, Arumugam M, Burgdorf KS, Manichanh C, et al. A human gut microbial gene catalogue established by metagenomic sequencing. Nature. 2010;464(7285):59-65.

4. Koenig JE, Spor A, Scalfone N, Fricker AD, Stombaugh J, Knight R, et al. Succession of microbial consortia in the developing infant gut microbiome. Proc Natl Acad Sci U S A. 2011;108 Suppl 1:4578-85.

5. Ito T, Sekizuka T, Kishi N, Yamashita A, Kuroda M. Conventional culture methods with commercially available media unveil the presence of novel culturable bacteria. Gut Microbes. 2019;10(1):77-91.

6. Rettedal EA, Gumpert H, Sommer MO. Cultivation-based multiplex phenotyping of human gut microbiota allows targeted recovery of previously uncultured bacteria. Nat Commun. 2014;5:4714.

7. Lane DJ. 16S/23S rRNA Sequencing. In: Stackebrandt E and Goodfellow M, Nucleic Acid Techniques in Bacterial Systematic, John Wiley and Sons, New York1991.

8. Stackebrandt E, Liesack W. Nucleic acids and classification. In: Goodfellow M and O'Donnell AG (ed.), Handbook of new bacterial systematics. Academic Press, London, England.1993.

9. Kim OS, Cho YJ, Lee K, Yoon SH, Kim M, Na H, et al. Introducing EzTaxon-e: a prokaryotic 16S rRNA gene sequence database with phylotypes that represent uncultured species. Int J Syst Evol Microbiol. 2012;62(Pt 3):716-21.

10. Kumar S, Stecher G, Tamura K. MEGA7: Molecular Evolutionary Genetics Analysis Version 7.0 for Bigger Datasets. Mol Biol Evol. 2016;33(7):1870-4.

11. Thompson JD, Higgins DG, Gibson TJ. CLUSTAL W: improving the sensitivity of progressive multiple sequence alignment through sequence weighting, position-specific gap penalties and weight matrix choice. Nucleic Acids Res. 1994;22(22):4673-80.

12. Felsenstein J. Evolutionary trees from DNA sequences: a maximum likelihood approach. $\mathbf{J}$ Mol Evol. 1981;17(6):368-76. 
13. Fitch WM. Toward Defining the Course of Evolution: Minimum Change for a Specific Tree Topology. Systematic Zoology 20(10):406-16.

14. Saitou N, Nei M. The neighbor-joining method: a new method for reconstructing phylogenetic trees. Mol Biol Evol. 1987;4(4):406-25.

15. Wick RR, Judd LM, Gorrie CL, Holt KE. Unicycler: Resolving bacterial genome assemblies from short and long sequencing reads. PLoS Comput Biol. 2017;13(6):e1005595.

16. Gurevich A, Saveliev V, Vyahhi N, Tesler G. QUAST: quality assessment tool for genome assemblies. Bioinformatics. 2013;29(8):1072-5.

17. Lee I, Ouk Kim Y, Park SC, Chun J. OrthoANI: An improved algorithm and software for calculating average nucleotide identity. Int J Syst Evol Microbiol. 2016;66(2):1100-3.

18. Kim M, Oh HS, Park SC, Chun J. Towards a taxonomic coherence between average nucleotide identity and 16S rRNA gene sequence similarity for species demarcation of prokaryotes. Int J Syst Evol Microbiol. 2014;64(Pt 2):346-51.

19. Shields P, Cathcart L. Motility test medium protocol. American Society for Microbiology. 2011.

20. Sasser M. Identification of Bacteria by Gas Chromatography of Cellular Fatty Acids. MIDI Technical Note 101 Newark, DE: MIDI Inc. 1990. 


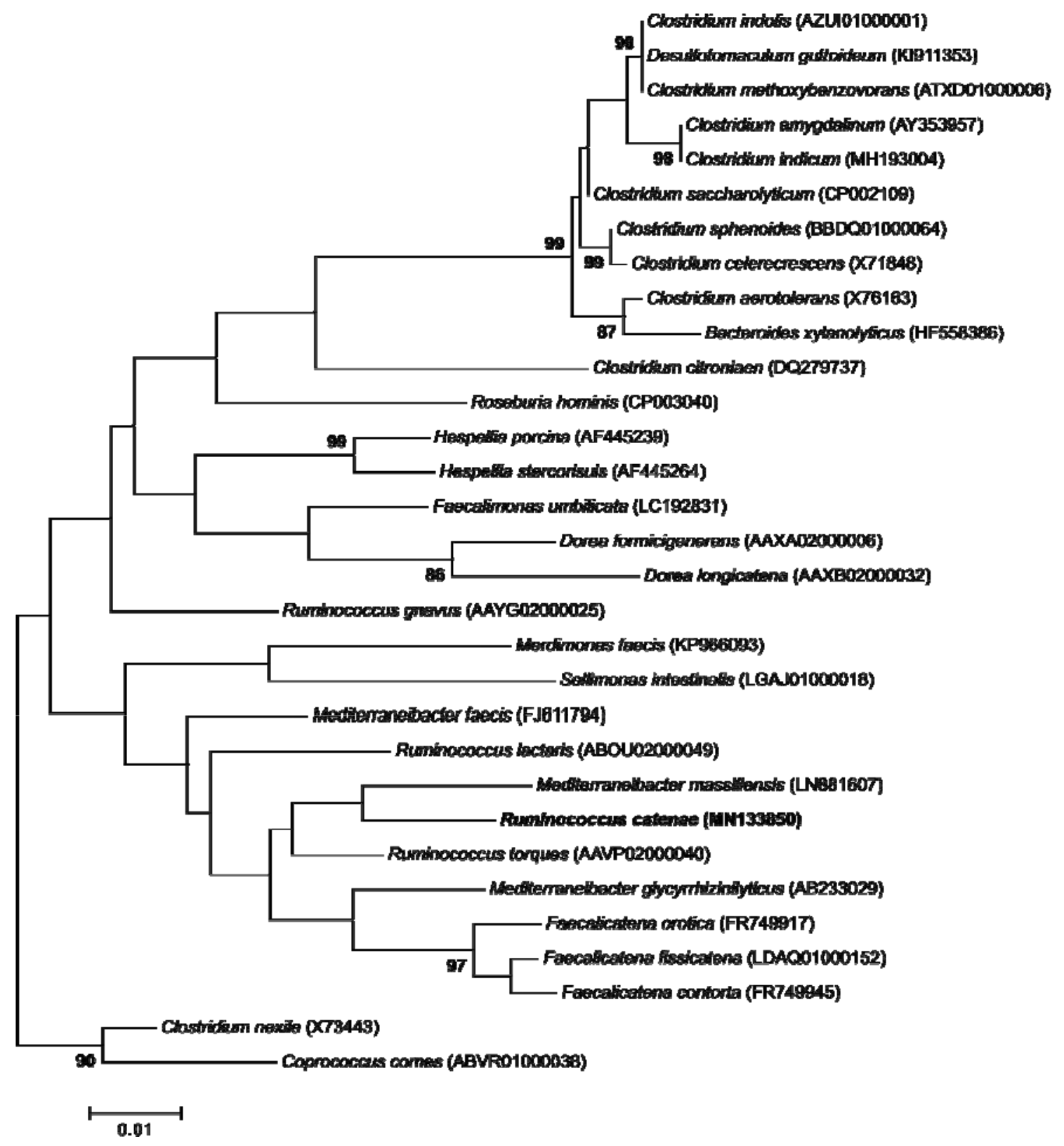

Fig. 1. Maximum likelihood based 16S rRNA gene phylogeny, showing the phylogenetic position of R. catenae sp. nov. $\left(=\operatorname{CCOS} 1886^{\mathrm{T}},=\mathrm{DSM} 109242^{\mathrm{T}}\right)$ with closely related taxa in the family Lachnospiraceae. GenBank accession numbers of the 16S rRNA gene sequences are given in parentheses. Bootstrap values (based on 1000 replications) greater than or equal to $70 \%$ are shown in percentages at each node. Bar, 0.01 substitutions per nucleotide position. 


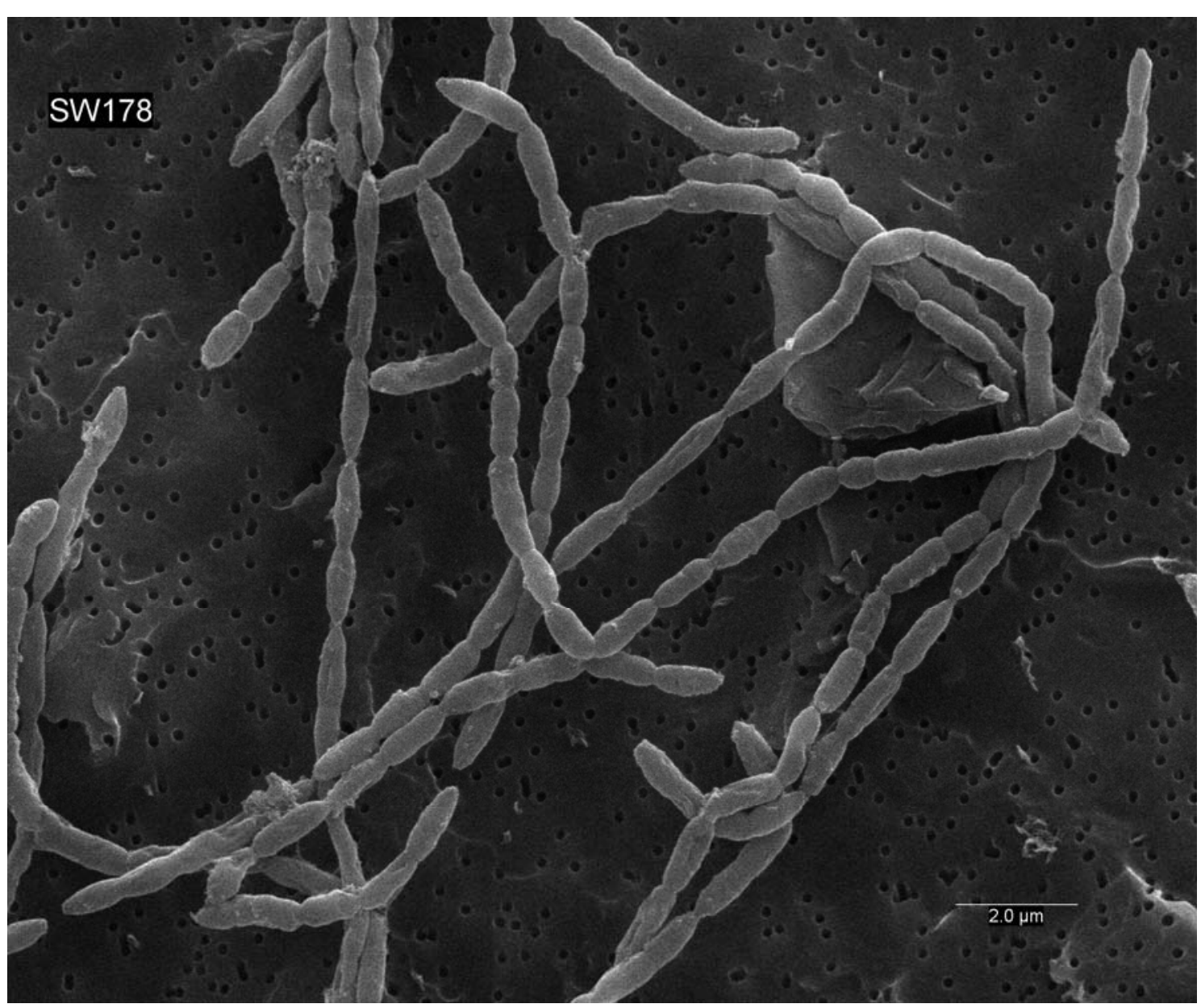

Fig. 2. Scanning electron micrograph of cells of Ruminococcus catenae sp. nov. Cells were anaerobically cultured for 1 day at $37^{\circ} \mathrm{C}$ in BHI-M medium. Bar, $10.0 \mu \mathrm{m}$ (a) and $2.0 \mu \mathrm{m}$ (b). 
Table 1. Characteristics of R. catenae sp. nov. $\left(=\operatorname{CCOS} 1886^{\mathrm{T}},=\mathrm{DSM} 109242^{\mathrm{T}}\right)$ and the closest related strain. Strains SW178 and Ruminococcus torques ATCC $27756^{\mathrm{T}}$ were anaerobically cultured in BHIM at $37{ }^{\circ} \mathrm{C}$ for 2 days. +, Positive; -, negative; w, weakly positive; ND, not detected.

\begin{tabular}{|c|c|c|}
\hline Characteristic & SW178 & $\mathrm{ATCC27756}^{\mathrm{T}}$ \\
\hline \multicolumn{3}{|l|}{ Gram stain } \\
\hline \multicolumn{3}{|l|}{ Growth at $45^{\circ} \mathrm{C}$} \\
\hline \multicolumn{3}{|l|}{$\mathrm{pH} 5$} \\
\hline \multicolumn{3}{|l|}{ Carbon source (BIOLOG AN) } \\
\hline Dextrin & + & - \\
\hline D-Fructose & - & + \\
\hline L-Fucose & + & + \\
\hline D-Galacturonic & + & - \\
\hline$\alpha$-D-Glucose & + & - \\
\hline Maltotriose & - & + \\
\hline D-Mannose & - & + \\
\hline D-Melezitose & - & + \\
\hline 3-Methyl-Dglucose & - & + \\
\hline Palatinose & - & + \\
\hline L-Rhamnose & + & + \\
\hline D-Sorbitol & + & - \\
\hline Stachyose & - & + \\
\hline Sucrose & - & + \\
\hline D-Trehalose & - & + \\
\hline Turanose & - & + \\
\hline Enzyme activity (API ZYM) & - & + \\
\hline Alkaline phosphatase & - & + \\
\hline Esterase (C 4) & + & - \\
\hline Esterase Lipase (C 8) & + & - \\
\hline Valine arylamidase & - & - \\
\hline Trypsin & - & - \\
\hline$\alpha$-chymotrypsin & - & $\mathrm{w}$ \\
\hline$\alpha$-galactosidase & - & - \\
\hline$\beta$-galactosidase & + & - \\
\hline$\beta$-glucuronidase & - & - \\
\hline$\alpha$-glucosidase & + & - \\
\hline$\beta$-glucosidase & + & - \\
\hline DNA G+C content $(\mathrm{mol} \%)$ & & \\
\hline
\end{tabular}


Table 2. Cellular fatty acid contents (\%) of strain R. catenae sp. nov. (= CCOS $1886^{\mathrm{T}}$, =DSM $109242^{\mathrm{T}}$ ) and its closest related strain. Strains SW178 and Ruminococcus torques ATCC $27756^{\mathrm{T}}$ were anaerobically cultured for 2 days in BHIM. Fatty acids comprising less than $1 \%$ of the total fatty acids in both strains is not shown.

\begin{tabular}{|lcc|}
\hline Fatty acid composition & SW178 & ATCC27756 $^{\mathbf{T}}$ \\
\hline Straight chain & & \\
$\mathrm{C}_{12: 0}$ & 1.31 & 2.9 \\
$\mathrm{C}_{14: 0}$ & 28.71 & 7.98 \\
$\mathrm{C}_{16: 0}$ & 19.55 & 23.58 \\
$\mathrm{C}_{16: 0}$ ALDE & 3.35 & 2.46 \\
$\mathrm{C}_{18: 0}$ & 1.15 & 9.96 \\
Demethylacetal (DMA) & & \\
$\mathrm{C}_{12: 0}$ DMA & & \\
$\mathrm{C}_{14: 0}$ DMA & 7.82 & 0.78 \\
$\mathrm{C}_{16: 0}$ DMA & 12.55 & 9.66 \\
$\mathrm{C}_{18: 0}$ DMA & 1.73 & 3.42 \\
$\mathrm{C}_{16: 1} \omega 7 c$ DMA & 2.41 & - \\
$\mathrm{C}_{18: 1} \omega 7 c$ DMA & 7.9 & - \\
Unsaturated & & 0.38 \\
$\mathrm{C}_{13: 1}$ at $12-13$ & 4.26 & 10.26 \\
$\mathrm{C}_{16: 1} \omega 7 c$ & 1.42 & 6.15 \\
$\mathrm{C}_{16: 1} \omega 9 c$ & - & 3.57 \\
$\mathrm{C}_{18: 1} \omega 7 c$ & 1.95 & 16.71 \\
$\mathrm{C}_{18: 1} \omega 9 c$ & 0.78 & 0.38 \\
Summed Feature 1 & 4.26 & \\
\hline
\end{tabular}

